\title{
Summary of the NACI Update on the Recommended Use of Hepatitis B Vaccine
}

\author{
B Henry ${ }^{1}$, O Baclic ${ }^{2}$ on behalf of the National Advisory Committee on Immunization (NACl)*
}

\begin{abstract}
Background: Infant and adolescent hepatitis B (HB) immunization programs have been successfully implemented in all Canadian provinces and territories since the 1990s. Following the introduction of universal immunization programs, the incidence of HB has decreased in all age groups. However, the duration of protection against chronic infection, as measured by preserved T- and B-cell memory, remains unknown.
\end{abstract}

Objectives: To review the evidence on long-term protection against HB in adolescents who received routine immunization in infancy, determine the level of risk of HB infection in Canadians with diabetes and assess the timing of re-vaccination of individuals with immunocompromising conditions.

Methods: The National Advisory Committee on Immunization (NACl) Hepatitis Working Group reviewed key questions and performed an evidence review and synthesis. In consideration of the burden of illness to be prevented, the target population and issues related to safety, immunogenicity, efficacy and effectiveness of the vaccine, the group proposed recommendations for vaccine use to $\mathrm{NACl}$. All evidence was rated and summarized in tables. $\mathrm{NACl}$ approved specific evidence-based recommendations and elucidated the rationale and relevant considerations in the Statement update.

Results: In addition to the epidemiological data assessment, $\mathrm{NACl}$ reviewed evidence from efficacy and effectiveness studies with up to 30 years of follow-up data as well as data from 39 publications on immune response following the administration of a HB booster dose in individuals who were immunized as infants. Based on the conducted review, NACl did not find evidence that would support a change to its current recommendation that there is no need for routine booster immunization of individuals immunized in infancy and that there is no evidence to support preferential immunization schedules or routine immunization of individuals with diabetes.

Conclusion: $\mathrm{NACl}$ now recommends that following immunization of immunocompromised individuals, initial annual monitoring of $\mathrm{HB}$ antibody levels may be considered.

\author{
Affiliations \\ ${ }^{1} \mathrm{NACl}$ Hepatitis Working Group \\ Chair, Victoria, BC \\ ${ }^{2}$ Centre for Immunization and \\ Respiratory Infectious Diseases \\ (CIRID), Public Health Agency of \\ Canada, Ottawa, ON
}

*Correspondence: naci-ccni@ phac-aspc.gc.ca

Suggested citation: Henry B, Baclic O. Summary of the NACl Update on the Recommended Use of Hepatitis B Vaccine. Can Commun Dis Rep. 2017;43(5):104-6. https://doi.org/10.14745/ccdr.v43i05a04

\section{Introduction}

In unvaccinated individuals, the risk of chronic hepatitis $B(\mathrm{HB})$ infection varies with age. Up to $95 \%$ of infants, $50 \%$ of children less than five years of age and $10 \%$ of adolescents and adults will develop a chronic infection (1). Although protection following a completed primary schedule is believed to be long lasting, the exact duration is not known. Presence of $\mathrm{T}$ - and B-cell memory is required for long-term protection (2-7). Following the introduction of universal immunization programs in all Canadian provinces and territories in the 1990s, the incidence of HB has decreased in all age groups (8). A summary of the current recommendations for HB vaccine is available in the Canadian Immunization Guide (9).

National Advisory Committee on Immunization (NACl) is a committee of immunization experts from across Canada that provides ongoing medical, scientific and public health advice to the Public Health Agency of Canada (PHAC) on vaccines authorized for sale in Canada. The NACI Hepatitis Working Group consists of $\mathrm{NACl}$ members, liaison members and other vaccine experts who systematically review and synthesize available scientific and other technical information (e.g. disease burden, vaccine characteristics, unpublished study data) pertaining to specific questions or issues concerning hepatitis $A$ and hepatitis $B$ vaccines (10).

\section{Methods}

The Hepatitis Working Group reviewed key questions and performed a review and synthesis of evidence on long-term 
protection against $\mathrm{HB}$ in adolescents who received routine immunization in infancy and the timing for re-vaccination of people with immunocompromising conditions. The group also reviewed epidemiological data and research evidence to determine the level of risk of HB infection in Canadians with diabetes. In consideration of the burden of illness to be prevented, the target population, safety, immunogenicity, efficacy and effectiveness of the vaccine, the Hepatitis Working Group proposed recommendations for vaccine use to $\mathrm{NACl}$. All evidence was rated and summarized in evidence tables. $\mathrm{NACl}$ approved specific evidence-based recommendations and elucidated the rationale and relevant considerations in the Statement Update.

\section{Results}

In 2013 , there were 0.5 cases of acute HB infection per 100,000 population and 12 cases of chronic HB infection per 100,000 population reported through the Canadian Notifiable Disease Surveillance System (CNDSS) (10). According to Canadian Health Measures Survey (CHMS) data, the prevalence of present HB infection in individuals 14 to 79 years of age is estimated to be $0.4 \%$, with the highest infection rate reported in non-white (1.8\%) and the foreign-born (1.6\%) populations (11).

Based on a review of studies with up to 30 years of data, $\mathrm{NACl}$ did not find evidence that would suggest reduced long-term vaccine effectiveness in individuals who were immunized as infants. In addition, $\mathrm{NACl}$ also reviewed 39 publications which reported data on immune memory following the administration of a HB challenge dose and did not find evidence that would support the need for a routine $\mathrm{HB}$ vaccine booster dose in routine immunization programs.

Based on the reviewed evidence, $\mathrm{NACl}$ issued four recommendations for the use of HB vaccines in Canada (see Text box).

\section{National Advisory Committee on Immunization (NACl) recommendations for the use of Hepatitis B vaccines in Canada}

Recommendation 1: NACl does not recommend routine booster doses of HB vaccine for immunocompetent individuals following the completion of a recommended HB immunization schedule given in infancy. (NACl Evidence Grade B Recommendation)

$\mathrm{NACl}$ concludes that there is fair evidence to make this recommendation, based on the limited information available through epidemiological and literature reviews summarized in this statement. Continuous, long-term assessment of enhanced epidemiological data for the appearance of acute disease or the HBsAg carrier state in immunized populations (general population and groups-atrisk) is required before revising current recommendations. National enhanced surveillance systems should, as a minimum, include information on: age, sex, comorbidities, vaccination and immigration status.

Recommendation 2: NACl recommends that adults with diabetes not be considered as a separate high risk group for immunization with HB vaccine. (NACl Evidence Grade I Recommendation)

$\mathrm{NACl}$ recommends $\mathrm{HB}$ vaccine for all individuals without contraindications who wish to decrease their risk of $\mathrm{HB}$, including individuals with Type 1 and Type 2 diabetes. American data suggest a higher prevalence of previous or current HB infection among adults with diabetes compared to adults without diabetes, but similar Canadian epidemiological data are lacking. As there are notable differences between health care systems in the USA and Canada, and there is no current indication of higher risk of infection for individuals with diabetes in the general Canadian population, $\mathrm{NACl}$ does not have sufficient evidence to consider these individuals a separate high risk group for immunization with $\mathrm{HB}$-containing vaccine. $\mathrm{NACl}$ will continue to monitor the evidence as it evolves.

Recommendation 3: For immunocompromised individuals, initial annual monitoring of HB antibody levels following HB immunization may be considered. (NACl Evidence Grade B Recommendation)

Optimal timing and frequency of further serological testing should be based on the severity of the immunocompromised state and whether the risk of HB is still present. In immunocompromised persons who initially responded to HB vaccine, booster immunization is required if anti-HBs titres fall below $10 \mathrm{IU} / \mathrm{L}$. This recommendation is in line with similar recommendations made by the US Advisory Committee on Immunization Practices (ACIP), World Health Organization (WHO) and Australia's national immunisation technical advisory group. For individuals with chronic kidney disease and on dialysis who are known to respond sub-optimally to HB vaccination and in whom anti-HBs concentrations decline rapidly, $\mathrm{NACl}$ has previously recommended annual evaluation of $\mathrm{HB}$ antibody levels.

Recommendation 4: Immunization with HB-containing vaccine should be provided according to determined provincial and territorial (P/T) schedules. (NACI Evidence Grade I Recommendation)

There are several authorized schedules for HB vaccines in Canada. Over the last 2 decades, all P/Ts have effectively implemented prenatal HB screening and at-risk infant immunization programs. With marked reductions in HB incidence that have been observed across Canada and no data demonstrating an obvious advantage of any of the used schedules, optimal timing of primary $\mathrm{HB}$ vaccination remains to be contingent on existing $\mathrm{P} / \mathrm{T}$ epidemiology and specific programmatic considerations. Epidemiological information demonstrating failure of universal prenatal screening and routine immunization programs (i.e. detection of HBV infection in infants and children awaiting immunization) should be collected and analysed on an ongoing basis, so that appropriate changes can be made to existing HB immunization programs as needed. 
A complete review of evidence and full $\mathrm{NACl}$ recommendations on the use of $\mathrm{HB}$ vaccine are published in the $\mathrm{NACl}$ Statement Update (10) and the hepatitis B vaccine chapter of the Canadian Immunization Guide (9).

\section{Conclusion}

$\mathrm{NACl}$ now recommends that, following immunization of immunocompromised individuals, initial annual monitoring of $\mathrm{HB}$ antibody levels may be considered.

\section{Authors' statement}

This statement was prepared by the Hepatitis Working Group: Henry B (Working Group Chair), Baclic O, Brophy J, Choudhri Y, Coleman G, Gilca V, Ismail S, Marchant-Short S, Pham-Huy A, Salvadori M, Warrington $\mathrm{R}$

\section{Conflict of interest}

None.

\section{Acknowledgements}

NACI members: Gemmill I (Chair), Quach C (Vice-Chair), Dayneka N, Deeks S, Henry B, Marchant-Short S, Salvadori M, Sicard N, Vaudry W, Vinh D, Warrington R

Liaison representatives: Blake $\mathrm{J}$ (Society of Obstetricians and Gynaecologists of Canada), Brophy J (Canadian Association for Immunization Research and Evaluation), Cohn A (Centers for Disease Control and Prevention, United States), Cole T (Canadian Immunization Committee), Emili J (College of Family Physicians of Canada), Lavoie M (Council of Chief Medical Officers of Health), Mah C (Canadian Public Health Association), Moore D (Canadian Paediatric Society), Pham-Huy A (Association of Medical Microbiology and Infectious Disease Canada)

Ex-officio representatives: Barnes K (National Defence and the Canadian Armed Forces), Charos G (Centre for Immunization and Respiratory Infectious Diseases [CIRID], Public Health Agency of Canada [PHAC]), Coleman G (Biologics and Genetic Therapies Directorate [BGTD], Health Canada [HC]), Gallivan J (Marketed Health Products Directorate [MHPD], HC), Pennock J (CIRID, $\mathrm{PHAC}$ ), Wong $\mathrm{T}$ (First Nations and Inuit Health Branch [FNIHB], $\mathrm{HC}$

\section{Funding}

The work of $\mathrm{NACl}$ is supported by Public Health Agency of Canada.

\section{References}

1. Hollinger F, Liang TJ. Hepatitis B virus. In: Knipe DM, Howley PM, Griffin DE, Lamb RA, Martin MA, Roizman B, et al, editors. Fields Virology. 4th ed. ed. Philadelphia, PA: Lippincott-Raven Publishers; 2001. p. 2971-3036.

2. Carollo M, Palazzo R, Bianco M, Pandolfi E, Chionne P, Fedele $G$, et al. Hepatitis $B$ specific $T$ cell immunity induced by primary vaccination persists independently of the protective serum antibody level. Vaccine. 2013;31(3):506-13.

3. do Livramento A, Schultz J, Batista KZ, Treitinger A, de Cordova CM, Spada C. Immune memory response induced in vitro by recombinant hepatitis B surface antigen challenge 13-18 years after primary vaccination. J Med Virol. 2014;86(10):1700-4.

4. Rosado MM, Scarsella M, Pandolfi E, Cascioli S, Giorda E, Chionne P, et al. Switched memory B cells maintain specific memory independently of serum antibodies: The hepatitis $B$ example. Eur J Immunol. 2011;41(6):1800-8.

5. Banatvala J, Van Damme P, Oehen S. Lifelong protection against hepatitis $B$ : The role of vaccine immunogenicity in immune memory. Vaccine. 2000;19(7-8):877-85.

6. Bauer T, Jilg W. Hepatitis B surface antigen-specific T and B cell memory in individuals who had lost protective antibodies after hepatitis B vaccination. Vaccine. 2006;24(5):572-7.

7. Simons BC, Spradling PR, Bruden DJ, Zanis C, Case S, Choromanski TL, et al. A longitudinal hepatitis $B$ vaccine cohort demonstrates long-lasting hepatitis $B$ virus (HBV) cellular immunity despite loss of antibody against HBV surface antigen. J Infect Dis. 2016 Apr 7; pii: jiw142. [Epub ahead of print].

8. Government of Canada [Internet]. Report on Hepatitis B and C in Canada: 2013. Figure 1. Reported number of cases and rates of acute HBV infection in Canada by sex, CNDSS, 2005-2013. Ottawa: PHAC; 2016 [updated 2016 Jul 29; cited 2017 Mar 14]. Available from: http://healthycanadians.gc.ca/publications/ diseases-conditions-maladies-affections/hepatitis-b-c2013-hepatite-b-c/index-eng.php\#f1.

9. Government of Canada [Internet]. Canadian Immunization Guide, Part 4, Active Vaccines, Hepatitis B. Ottawa: PHAC [cited 2017 Mar 17]. Available from: https://www.canada. ca/en/public-health/services/publications/healthy-living/ canadian-immunization-guide-part-4-active-vaccines/page7-hepatitis-b-vaccine.html.

10. Government of Canada [Internet]. National Advisory Committee on Immunization Statement Update on the recommended use of hepatitis B vaccine. Ottawa: PHAC; 2017 [cited 2017 Mar 17]. Available from: https://www.canada.ca/en/public-health/ services/publications/healthy-living/update-recommende d-use-hepatitis-b-vaccine.html.

11. Statistics Canada [Internet]. Seroprevalence of hepatitis $B$ and C virus infections: Results from the 2007 to 2009 and 2009 to 2011 Canadian Health Measures Survey. Ottawa: PHAC [updated 2015 Nov 27; cited 2017 Mar 14]. Available from: http:// www.statcan.gc.ca/pub/82-003-x/2013011/article/11876eng.htm. 